\title{
Structural Modification of Alkali Tellurite Binary Glass System and Its Characterization
}

\author{
Kyu Ho Lee, Tae Ho Kim, Young Seok Kim, Young Joon Jung, Young Hoon Na and Bong Ki Ryu ${ }^{\dagger}$ \\ Division of Materials Science and Engineering, Pusan National University, Busan 609-735, Korea
}

(Received March 12, 2008 : Accepted April 28, 2008)

\begin{abstract}
This paper presents results and observations obtained from a study of the optical and thermal properties of alkali tellurite depending on the composition. Fourier transform infrared (FT-IR) spectra showed evidence of chemical modification from $\mathrm{TeO}_{4}$ trigonal bipyramids (tbp) to $\mathrm{TeO}_{3}$ trigonal pyramids (tp) in tellurite glasses. The optical band gaps of the different glass samples calculated using Tauc's method were found to range from 3.5-3.8 eV. The glass transition temperature (Tg) and glass stability $(\Delta \mathrm{T})$ of alkali tellurite glasses were investigated, as $\mathrm{M}_{2} \mathrm{O}$ [M: $\mathrm{Li}, \mathrm{Na}, \mathrm{K}$ ] amounted to $25 \mathrm{~mol} \%$, through the use of differential thermal analysis (DTA). The coefficient of thermal expansion (CTE) was measured in a thermo mechanical analysis (TMA) with a slow heating rate after the glass samples were annealed. The results confirm that the optical band gap of alkali tellurite glasses depends on the Te-O-Te structural relaxation related to the ratio of bridging/ non bridging oxygen (BO/NBO). In contrast, the thermal properties are related to the ionic field strength of the Te-O-M and M-O-M bonds, and the Te-O-Te breakage depends on the ratio of BO/NBO.
\end{abstract}

Key words Tellurite glass, FT-IR, DTA, CTE, Optical band gap.

\section{Introduction}

In recent years, glasses doped with rare earth ion (RE) have been studied with much attention for optical devices (optical lasers and amplifiers, sensors and optical switching) due to their interesting optical properties ${ }^{1,2)}$ contributed to the sharp spectral lines of RE ions by the transitions between levels inside the $4 \mathrm{f}$ electronic shell. ${ }^{3)}$

Chalcogenide and Tellurite glasses have been much considered as a candidate host glass composition with containing RE ion, due to the high solubility of RE ions and the low phonon energy for maximizing the quantum efficiency of photoluminescence., ${ }^{4)}$

Especially, it is well known that the tellurite glass has more profitable properties for optical devices, because of their high refractive index, high transmittance in infrared region and high chemical durability as well as relatively easy technique to melt glasses. ${ }^{6-8)}$

Alkali ions $\left[\mathrm{M}_{2} \mathrm{O}, \mathrm{M}\right.$ : $\left.\mathrm{Li}, \mathrm{Na}, \mathrm{K}\right]$ take a role as a network modifier in tellurite glass so that it induces the low melting temperature and a good glass stability according to Zachariasen's rules. ${ }^{9)}$ However, the optical transitions between $4 \mathrm{f}-5 \mathrm{~d}$ levels which is main mechanism of

Corresponding author

E-Mail : bkryu@pusan.ac.kr (B. K. Ryu) photoluminescence of RE activate ion are so sensitive to host glass composition that it is important to investigate the change of glass properties.

For clarifying the structure of the tellurite glasses, many kinds of the works has been done so far. Dimitriev et al. and Sakida et al. have suggested that the basic structural units have been $\mathrm{TeO}_{4}$ trigonal bipyramids (tbp) and $\mathrm{TeO}_{3}$ trigonal pyramids (tp) in tellurite glasses by using a nuclear magnetic resonance (NMR) and an extended X-ray Absorption Fine Structure (EXAFS). Moreover, they have shown that the $\mathrm{TeO}_{3}$ fraction increased at the expense of the $\mathrm{TeO}_{4}$ units, as network modifier oxides were added, due to the formation of nonbridging oxygen sites ${ }^{10 \sim 13)}$

In this work, as the $\mathrm{M}_{2} \mathrm{O}[\mathrm{M}: \mathrm{Li}, \mathrm{Na}, \mathrm{K}]$ added in $\mathrm{TeO}_{2}$ based glass up to $25 \mathrm{~mol} \%$, we have investigated the change of some properties of the glasses and explained the phenomenon with relating to the chemical modification of $\mathrm{TeO}_{4}$ trigonal bipyramids.

\section{Experimental procedure}

$\mathrm{TeO}_{2}$ and alkali oxide form $\mathrm{Li}_{2} \mathrm{CO}_{3}, \mathrm{Na}_{2} \mathrm{CO}_{3}$, and $\mathrm{K}_{2} \mathrm{CO}_{3}$ with purities higher than $99.9 \%$ were weighed as the following compositions:

$$
x \mathrm{Li}_{2} \mathrm{O} \cdot(100-x) \mathrm{TeO}_{2}(\mathrm{~mol} \%)
$$




$$
\begin{aligned}
& x \mathrm{Na}_{2} \mathrm{O} \cdot(100-\mathrm{s} x) \mathrm{TeO}_{2}(\mathrm{~mol} \%) \\
& x \mathrm{~K}_{2} \mathrm{O} \cdot(100-x) \mathrm{TeO}_{2}\left(\mathrm{~mol}^{2}\right) \\
& {[x=10,15,20,25,30]}
\end{aligned}
$$

All weighed chemical powders were finely mixed for 10 minutes. Each batch $(10 \mathrm{~g})$ was melted in platinum crucibles in an electrical furnace at $1000^{\circ} \mathrm{C}$ for $30 \mathrm{~min}$. These melts were quenched on steel plate and the transparent pale yellow samples were obtained. The asquenched glasses were ground and screened to obtain glass powder.

DTA was performed to obtain the thermal properties (Tg, Ts, Tx) of the glasses by using Shimazu DTA-60 with heating rate of $10^{\circ} \mathrm{C} / \mathrm{min}$. The coefficients of thermal expansion (CTE) of the glasses were obtained by thermo mechanical analysis (TMA) using Shimazu TMA60 with heating rate of $2^{\circ} \mathrm{C} / \mathrm{min}$.

UV-VIS spectrometer was used to calculate the optical band gap of the glass samples by using Agilent 8453 UV-VIS spectrometer with a halogen light source.

Infrared (IR) measurements were performed on glass powder samples dispersed in pressed $\mathrm{KBr}$ pellets using a Nicolet Nexus 670 FTIR spectrometer. The spectra were recorded in transmission mode at 32 scans with $4 \mathrm{~cm}^{-1}$ resolution in the $1000-400 \mathrm{~cm}^{-1}$ range.

\section{Results \& Discussion}

\subsection{FT-IR Spectra}

Sakida et al. have investigated the structures of pure $\mathrm{TeO}_{2}$ and $\mathrm{M}_{2} \mathrm{O}-\mathrm{TeO}_{2}$ glasses by using NMR. They have suggested that the pure $\mathrm{TeO}_{2}$ glass consisted of $\mathrm{TeO}_{4}$ trigonal bipyramids (tbp) in which one equatorial site has been occupied by a lone pair of electrons, while the other two equatorial and axial sites have been occupied by oxygen atoms. Fig. 1 shows they have also shown that the Te coordination polyhedron has been changed from $\mathrm{TeO}_{4}$ tbp to $\mathrm{TeO}_{3}$ tp in addition of the $\mathrm{M}_{2} \mathrm{O}$ to the pure $\mathrm{TeO}_{2}$ glass, called chemical modification.

Heo et al. have invested the structural modification of tellurite glasses by using FT-IR. ${ }^{14)}$ They have shown a strong absorption band at $620 \mathrm{~cm}^{-1}$ with a small shoulder and a shift as large as $20 \mathrm{~cm}^{-1}$, as $\mathrm{Na}_{2} \mathrm{O}$ increased in the $\mathrm{Na}_{2} \mathrm{O}-\mathrm{TeO}_{2}$ system.

Fig. 2 shows the FT-IR spectra changes of alkali tellurite glass. From this result, we have observed the strong absorption of the stretching vibration of $\mathrm{Te}-\mathrm{O}_{\mathrm{ax}}$ bond in deformed $\mathrm{TeO}_{4}$ trigonal bipyramid units from $620 \mathrm{~cm}^{-1}$ to $550 \mathrm{~cm}^{-1}$, as well as the vibration of Te-O bond in $\mathrm{TeO}_{3}$ trigonal pyramids units from $730 \mathrm{~cm}^{-1}$ to $780 \mathrm{~cm}^{-1}$. As the $\mathrm{M}_{2} \mathrm{O}$ increased in alkali tellurite glass, the absorption intensity of $\mathrm{Te}-\mathrm{O}$ bond in $\mathrm{TeO}_{3}$ trigonal pyramids units around $750 \mathrm{~cm}^{-1}$ band was getting higher, while the intensity of $\mathrm{TeO}_{4}$ absorption band around $620 \mathrm{~cm}^{-1}$ was getting lower. Beside this, the $\mathrm{TeO}_{4}$ vibration band was shifted to the lower frequency and the $\mathrm{TeO}_{3}$ vibration band was shifted to the higher frequency due to the chemical modification of from $\mathrm{TeO}_{4}$ tbp to $\mathrm{TeO}_{3}$ tp. All of these phenomenons have well indicated the breakage of the Te-O-Te network bridges which have been accompanied by the formation of non-bridging oxygen with increasing the $\mathrm{TeO}_{3}$ fraction at the expense of the $\mathrm{TeO}_{4}$ units.

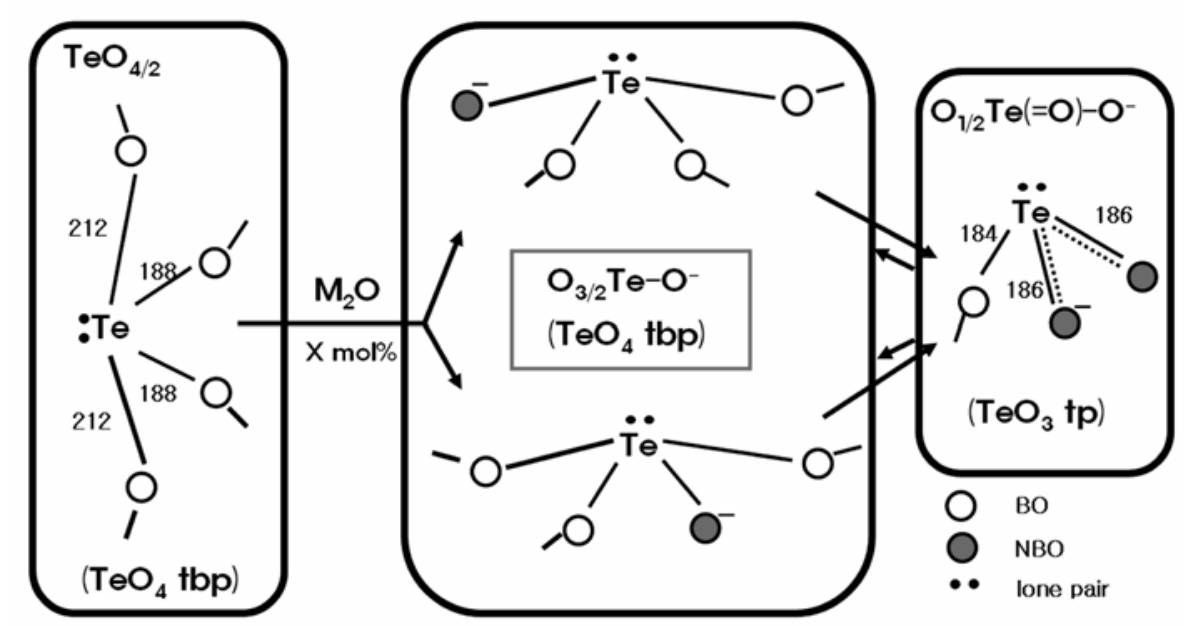

Fig. 1. A model showing a structural modification of the tellurite glass. ${ }^{12)}$ 

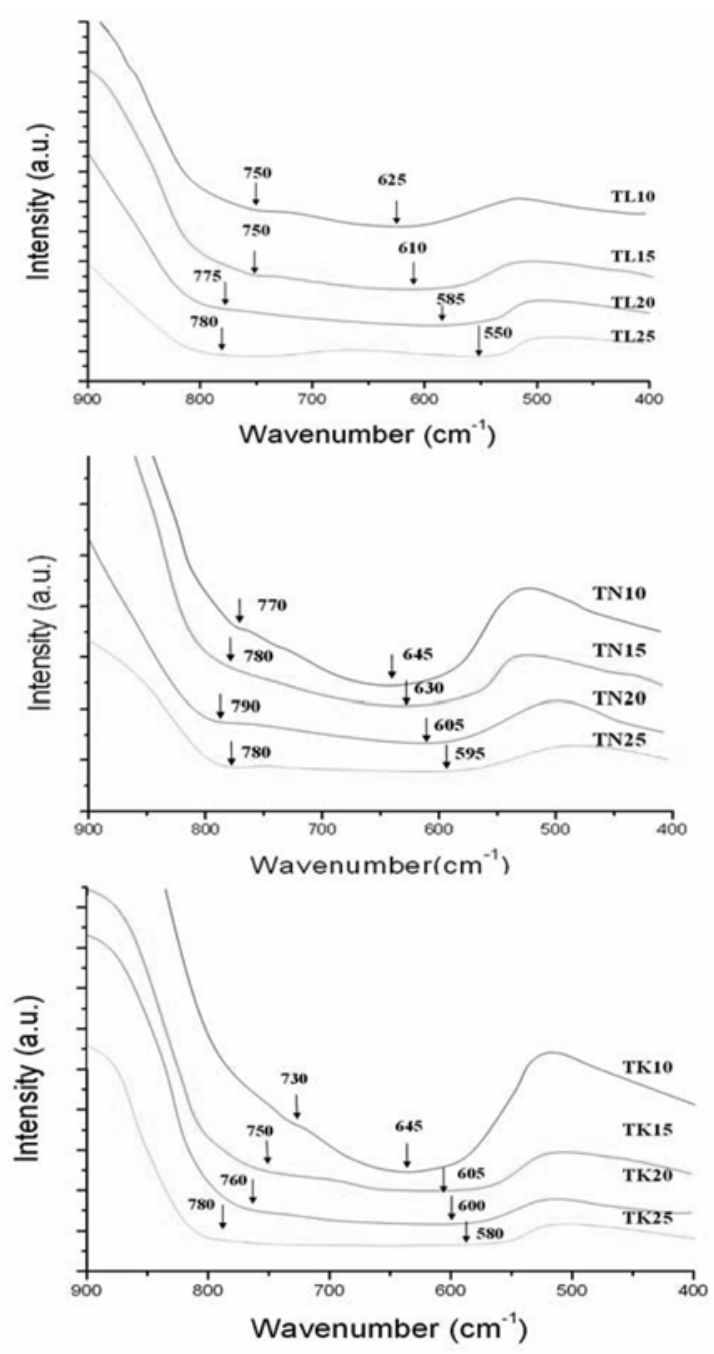

Fig. 2. FT-IR spectra of the alkali tellurite glasses.

\subsection{Optical Band Gap}

Fig.3 shows the optical band gaps of alkali tellurite glasses. The optical energy band gaps of these glasses were calculated by Tauc's equation as following: ${ }^{15)}$

$$
\alpha(v) h v \approx\left(h v-\mathrm{E}_{\mathrm{g}}\right)^{1 / 2}
$$

Where, $h v$ is photon energy and $\alpha(v)$ is absorption coefficient which was calculated by Lambert-beer equation as following:

$$
T / T_{0}=e^{-a d}
$$

Where, $T$ is sample's transmittance, $T_{0}$ is blank's transmittance, $\alpha$ is absorption coefficient and $d$ is sample's thickness.

As shown in Fig. 3, the entire optical band gap was getting wider, as the network modifier increased. In the
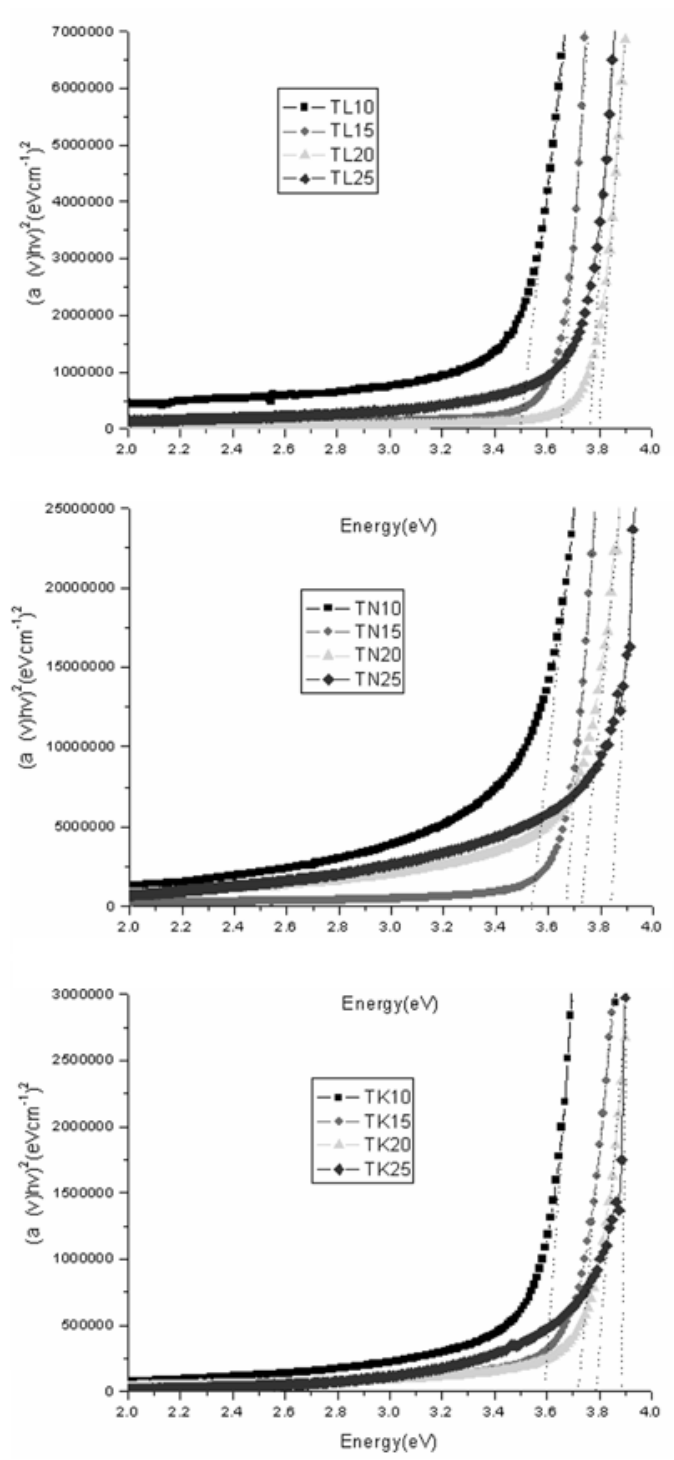

Fig. 3. The changes of the alkali tellurite glasses depending on the $\mathrm{M}_{2} \mathrm{O}$ concentration.

$\mathrm{Li}_{2} \mathrm{O}-\mathrm{TeO}_{2}$ binary system, the optical band gap increased from 3.5 to $3.8 \mathrm{eV}$ due to the addition of $\mathrm{Li}_{2} \mathrm{O}$ up to $25 \mathrm{~mol} \%$. When the $\mathrm{Na}_{2} \mathrm{O}$ was added as the network modifier, the optical band gap was increased from 3.55 to $3.85 \mathrm{eV}$. Incase of the $\mathrm{K}_{2} \mathrm{O}-\mathrm{TeO}_{2}$ binary system, the optical band gap showed in the region from 3.6 to $3.9 \mathrm{eV}$. These results showed that the range of the optical band gap revealed at the higher photon energy, as the radius of alkali ion increased. However, there were no differences of the increasing rate $(\Delta \mathrm{Eg} / \mathrm{mol})$ regardless of the type of alkali oxides. Dayanand et al. have suggested that the absence of the long range order contributed from the local inhomogeneities related to the ratio of $\mathrm{BO} / \mathrm{NBO}$ has played an important role in deciding the optical band gap 
Table 1. The properties of the alkali tellurite glasses

\begin{tabular}{|c|c|c|c|c|c|c|c|c|c|}
\hline & & \multicolumn{2}{|c|}{ Composition $(\mathrm{mol} \%)$} & \multicolumn{6}{|c|}{ Properties } \\
\hline & & $\mathrm{TeO}_{2}$ & $\mathrm{Li}_{2} \mathrm{O}$ & $\operatorname{Tg}\left({ }^{\circ} \mathrm{C}\right)$ & Ts $\left({ }^{\circ} \mathrm{C}\right)$ & $\mathrm{Tx}\left({ }^{\circ} \mathrm{C}\right)$ & $\Delta \mathrm{T}\left({ }^{\circ} \mathrm{C}\right)$ & $\begin{array}{c}\text { CTE } \\
\left(\times 10^{-7} /{ }^{\circ} \mathrm{C}\right)\end{array}$ & Eopt $(\mathrm{eV})$ \\
\hline \multirow{4}{*}{$\begin{array}{l}\text { TL Binary } \\
\text { System }\end{array}$} & TL10 & 90 & 10 & 276 & 287 & 310 & 34 & 185 & 3.5 \\
\hline & TL15 & 85 & 15 & 271 & 280 & 309 & 38 & 198 & 3.65 \\
\hline & TL20 & 80 & 20 & 261 & 271 & 309 & 48 & 207 & 3.75 \\
\hline & TL25 & 75 & 25 & 256 & 265 & 297 & 41 & 215 & 3.8 \\
\hline \multirow{5}{*}{$\begin{array}{l}\text { TN Binary } \\
\text { System }\end{array}$} & & $\mathrm{TeO}_{2}$ & $\mathrm{Na}_{2} \mathrm{O}$ & & & & & & \\
\hline & TN10 & 90 & 10 & 279 & 290 & 312 & 32 & 189 & 3.55 \\
\hline & TN15 & 85 & 15 & 268 & 278 & 308 & 40 & 202 & 3.6 \\
\hline & TN20 & 80 & 20 & 250 & 261 & 376 & 126 & 224 & 3.7 \\
\hline & TN25 & 75 & 25 & 241 & 249 & 306 & 65 & 241 & 3.85 \\
\hline \multirow{5}{*}{$\begin{array}{l}\text { TK Binary } \\
\text { System }\end{array}$} & & $\mathrm{TeO}_{2}$ & $\mathrm{~K}_{2} \mathrm{O}$ & & & & & & \\
\hline & TK10 & 90 & 10 & 269 & 285 & 346 & 77 & 198 & 3.6 \\
\hline & TK15 & 85 & 15 & 257 & 266 & 256 & 98 & 211 & 3.7 \\
\hline & TK20 & 80 & 20 & 230 & 241 & 272 & 41 & 237 & 3.8 \\
\hline & TK25 & 75 & 25 & 218 & 235 & 246 & 28 & 261 & 3.85 \\
\hline
\end{tabular}

of the glasses, because the relaxation of glass structure leaded to the decrease of photon's mobility. ${ }^{16)}$ It have designated that some factors such as the difference of the ionic field strength have not contributed to the optical band gap of the glass.

\subsection{Glass transition temperature}

The glass transition ( $\mathrm{Tg}$ ) and the softening temperature of alkali tellurite (Ts) are shown in Table 1, as changing the concentration of the $\mathrm{M}_{2} \mathrm{O}[\mathrm{M}: \mathrm{Li}, \mathrm{Na}, \mathrm{K}]$. In the $\mathrm{Li}_{2} \mathrm{O}-\mathrm{TeO}_{2}$ binary system, $\mathrm{Tg}$ was decreased slightly from $276^{\circ} \mathrm{C}$ to $256^{\circ} \mathrm{C}$ when the $\mathrm{Li}_{2} \mathrm{O}$ increased up to $25 \mathrm{~mol} \%$. The glass stabilities $(\Delta \mathrm{T}=\mathrm{Tx}-\mathrm{Tg})$ were shown similar values due to no significant change of nucleation temperature. In the $\mathrm{Na}_{2} \mathrm{O}-\mathrm{TeO}_{2}$ binary system, $\mathrm{Tg}$ was decreased from $279^{\circ} \mathrm{C}$ to $241^{\circ} \mathrm{C}$ as the ratio of $\mathrm{BO} / \mathrm{NBO}$ changed. However, the glass stability of the $20 \mathrm{Na}_{2} \mathrm{O}-$ $80 \mathrm{TeO}_{2}(\mathrm{~mol} \%)$ glass was shown a higher value than $100^{\circ} \mathrm{C}$ due to the shift of nucleation temperature caused by the different crystalline structure. In the $\mathrm{K}_{2} \mathrm{O}-\mathrm{TeO}_{2}$ binary system, the glass stability was decreased as a result of the shift to lower nucleation temperature. $\mathrm{Tg}$ and $\mathrm{Ts}$ of the $\mathrm{K}_{2} \mathrm{O}-\mathrm{TeO}_{2}$ glasses were decreased more significantly than the $\mathrm{Li}_{2} \mathrm{O}-\mathrm{TeO}_{2}$ and $\mathrm{Na}_{2} \mathrm{O}-\mathrm{TeO}_{2}$ binary system.

Fig. 4 shows the change of $\mathrm{Tg}$. In the glass science fields, the additivity principle has been used to calculate the glass properties so far. The additivity principle implies that the relation between the glass composition and a specific property is linear to all glass component concentrations with $\mathrm{Ci}$ and $\mathrm{Pi}$ representing specific glass component concentrations and related coefficients respectively in the equation below.

$$
\text { Additivity Principle: Glass propertie }=\mathrm{P}_{0}+\sum_{\mathrm{i}=1}^{\mathrm{n}} \mathrm{P}_{\mathrm{i}} \mathrm{C}_{\mathrm{i}}
$$

Thus, we have used the least squares line in order to approximate the linear relation between the glass properties and their composition by using the below equation.

The Least Squares Line: $y=a+b x$,

$$
\min =\sum_{\mathrm{i}=1}^{\mathrm{n}}\left[\mathrm{y}-\left(\mathrm{a}_{\mathrm{i}}+\mathrm{bx}_{\mathrm{i}}\right)\right]^{2}
$$

Where, $a, b$ are unknown coefficients while $x_{i}$ and $y_{i}$ are given from the experimental data.

In Fig. 4, as the $\mathrm{M}_{2} \mathrm{O}$ concentration increased, the decreasing rates of $\mathrm{Tg}$ were getting higher in order of $\mathrm{Li}<$ $\mathrm{Na}<\mathrm{K}$. The linear changes of glass transition temperatures are following:

$$
\begin{aligned}
& \mathrm{Li}_{2} \mathrm{O}-\mathrm{TeO}_{2}:-1.4^{\circ} \mathrm{C} / \mathrm{mol} \\
& \mathrm{Na}_{2} \mathrm{O}-\mathrm{TeO}_{2}:-2.6^{\circ} \mathrm{C} / \mathrm{mol} \\
& \mathrm{K}_{2} \mathrm{O}-\mathrm{TeO}_{2}:-3.6^{\circ} \mathrm{C} / \mathrm{mol}
\end{aligned}
$$

If the effects of the $\mathrm{M}_{2} \mathrm{O}$ on the ratio of $\mathrm{NBO} / \mathrm{BO}$ in the glass are equal regardless of the type of alkali ion, this result could be explained by the IFS (ionic field strength) depending on the ionic radius of alkali ion. 


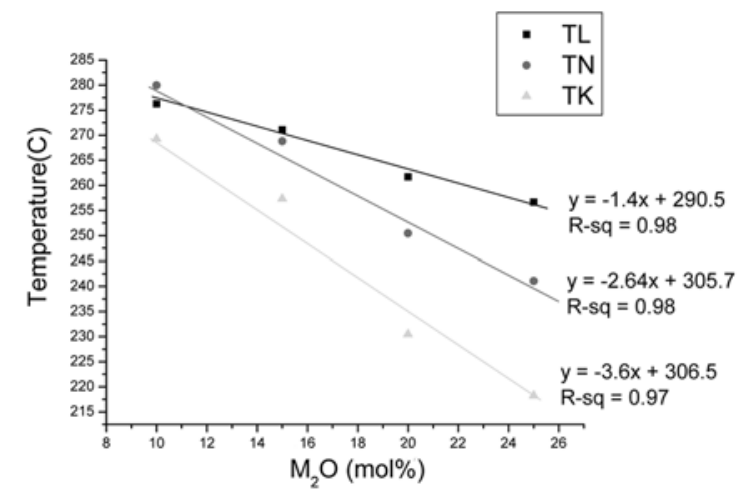

Fig. 4. The changes of glass transition temperature in the alkali tellurite glasses system.

Even though the valences of each alkali ions are equal, the IFSs are different due to the different ionic radius. According to the ionic field theory by Dietzel et al., the IFS of M-O bonds calculated by Eq. 5 were $0.25(\mathrm{Li}-\mathrm{O})$, $0.19(\mathrm{Na}-\mathrm{O}), 0.13(\mathrm{~K}-\mathrm{O}){ }^{17}{ }^{17}$

IFS (Ionic Field Strength) $=\mathrm{z}_{1} \mathrm{z}_{2} e^{2} /\left(\mathrm{r}_{1}+\mathrm{r}_{2}\right)$

Where, $Z_{1}, Z_{2}$ are the valence of ions, $e$ is electron charge, $r_{1}, r_{2}$ are the radius of ions. Therefore, the weaker IFS between alkali ion and non-bridging oxygen, the easier structural releases related to glass transition could be generated. Thus, this tendency was in a good agreement with the ionic field theory.

\subsection{Coefficient of Thermal Expansion}

The tendency related to the IFS was also shown in the change of thermal expansion coefficient (CTE) as shown in Fig. 5. The tellurite glasses were so unstable against rapid thermal expansion that TMA (thermo mechanical analysis) was conducted with a slow heating rate of $2^{\circ} \mathrm{C} /$ min after annealing below $\mathrm{Tg}$ for 3 hours. The $\mathrm{CTE}$ curves were shown in errors by less than $5 \%$.

As shown in Fig. 5, the thermal expansion of glass was increased as the $\mathrm{M}_{2} \mathrm{O}$ concentration increased, and the changing rates of the CTE showed a higher value in order of $\mathrm{Li}<\mathrm{Na}<\mathrm{K}$ due to the lower IFS attributing to the higher non-harmonic lattice's vibration in glass structure. $^{18)}$

\section{Conclusion}

In this study, we have investigated the optical and thermal properties of the binary alkali tellurite glasses, as the $\mathrm{M}_{2} \mathrm{O}$ [M: $\left.\mathrm{Li}, \mathrm{Na}, \mathrm{K}\right]$ added up to $25 \mathrm{~mol} \%$. From the

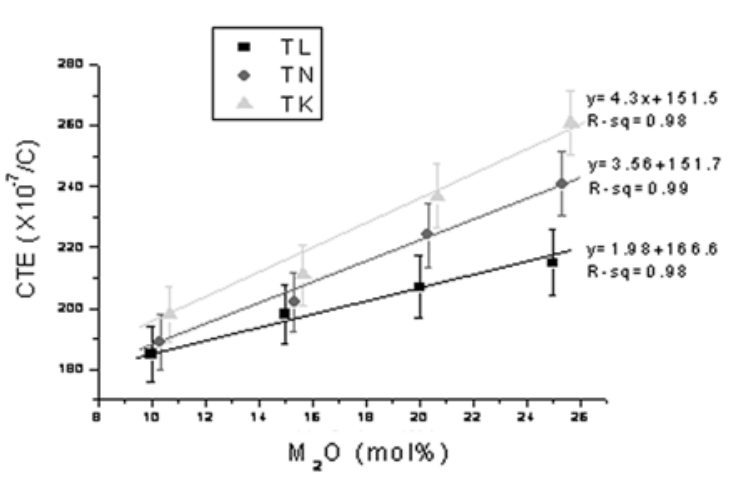

Fig. 5. The coefficient of thermal expansions of the alkali tellurite glasses depending on the $\mathrm{M}_{2} \mathrm{O}$ concentration.

FT-IR spectra, we have confirmed the structural modification from $\mathrm{TeO}_{4}$ trigonal bipyramids (tbp) to $\mathrm{TeO}_{3}$ trigonal pyramids (tp). The optical band gaps which were depended on the Te-O-Te breakage were increased, as the ratio of $\mathrm{BO} / \mathrm{NBO}$ changed. However, it was not related with the types of alkali ions. Contrarily, the thermal properties of alkali tellurite glass were related to the chemical modification of the Te-O-Te bonds as well as the Te-O-M and M-O-M bonds depending on the ionic field strength. In other words, even though the changes of the thermal properties showed the similar tendency, their changing rates were different due to the different M-O field strengths contributed from the each radius of the alkali ion.

\section{Acknowledgments}

This work was supported by a grant-in-aid for the National Core Research Center Program from the Ministry of Science \& Technology and the Korea Science \& Engineering Foundation (R15-2006-022-02001-0).

\section{References}

1. H. Lin, D. Yang, G. Liu, T. Ma, B. Zhai, Q. An, J. Yu, X. Wang, X. Liu and E. Y. Pun, J. Lumin. 113, 121 (2005).

2. Z. Assefa, R.G. Haire and P.E. Raison, Spectrochim. ActaA 60 (2004).

3. B. M. Walsh In: B. Di Bartoloand O. Forte, Editors, Advances in Spectroscopy for Lasers and Sensing, Springer, Netherlands (2006), p. 403

4. G. Poirier, F. C. Cassanges, C. B. de Arau' jo, V. A. Jerez, S. J. L. Ribeiro, Y. Messaddeq and M. Poulain, J. Appl. Phys., 93, 3259 (2003).

5. R. de Almeida, D. M. daSilva, L. R. P. Kassab, C. B. de Arau'jo, Optics Communications, 281, 108 (2008).

6. S. H. Kim, T. Yoko, J. Am. Ceram. Soc., 78, 1061 (1995).

7. G. V. Prakash, D. N. Rao andA. K. Bhatnagar, Solid State 
Commun. 119, 39 (2001).

8. H. G Kim, B. K. Ryu, J. M. Cha, B. K. Kim and L. S. Lee, J. Kor. Ceram. Soc., 40 (11), 1078 (2003).

9. S. H. Kim, T. Yoko and S. Sakka, J. Am. Ceram. Soc., 76, 2486 (1993).

10. Y. Dimitriev, V. Dimitrov, Mater. Res. Bull., 13, 1071 (1978).

11. Y. Dimitriev, V. Dimitrov and M. Arnaudov, J. Mater. Sci., 18, 1353 (1983).

12. S. Sakida, S. Hayakawa, T. Yoko J. Phys.: Condens. Matter, 12, 2579 (2000).

13. S. Sakida, S. Hayakawa, T. Yoko, J. Am. Ceram. Soc., 84,
836 (2001).

14. J. Heo, D. Lam, G. H. Sigel, E.A. Mendoza, D. A. Hensley, J. Am. Ceram. Soc., 75, 277 (1992).

15. H. FritzsheIn: J. Tauc, Editor, Amorphous and Liquid Semiconductors, Plenum, London (1974), p. 221.

16. C. Dayanand, R. V. G. K. Sarma, G. Bhikshamaiah, M. Salagram, J. Non-Cryst. Solids, 167, 122 (1994).

17. A. Dietzel, Z. Elektrochem. Angew Physik Chem, 48, 9 (1942).

18. L. Shartis, S. Spinner and W. Capps, J. Am. Ceram. Soc., 35, 155 (1952). 